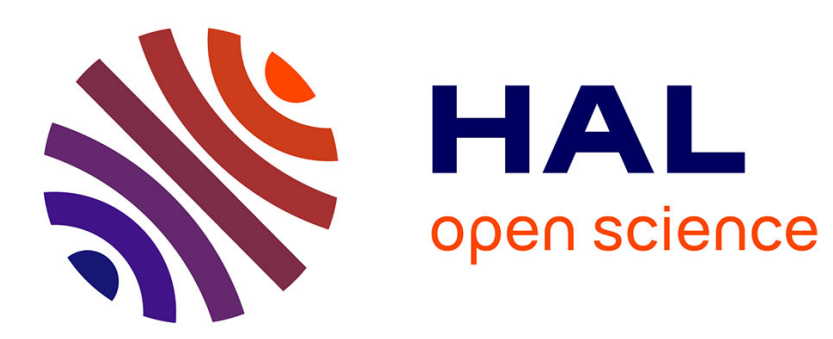

\title{
Early detection of thermal contrast in pulsed stimulated thermography
}

\author{
J.-C. Krapez, F. Lepoutre, D. Balageas
}

\section{To cite this version:}

J.-C. Krapez, F. Lepoutre, D. Balageas. Early detection of thermal contrast in pulsed stimulated thermography. Journal de Physique IV Proceedings, 1994, 04 (C7), pp.C7-47-C7-50. 10.1051/jp4:1994712 . jpa-00253173

\section{HAL Id: jpa-00253173 https://hal.science/jpa-00253173}

Submitted on 1 Jan 1994

HAL is a multi-disciplinary open access archive for the deposit and dissemination of scientific research documents, whether they are published or not. The documents may come from teaching and research institutions in France or abroad, or from public or private research centers.
L'archive ouverte pluridisciplinaire HAL, est destinée au dépôt et à la diffusion de documents scientifiques de niveau recherche, publiés ou non, émanant des établissements d'enseignement et de recherche français ou étrangers, des laboratoires publics ou privés. 


\title{
Early detection of thermal contrast in pulsed stimulated thermography
}

\author{
J.-C. Krapez, F. Lepoutre and D. Balageas \\ L3C Laboratory, ONERA, 92322 Châtillon cedex, France
}

\begin{abstract}
Stimulated Infrared Thermography (TIS) is a fast and global method for NonDestructive Evaluation (NDE). Among the recently emerging NDE methods, it is probably the less intrusive one since it really needs no contact at all with the tested structure. A new inversion technique, using an early detection of the contrast, is presented to demonstrate how it recovers the depth of the defects with accuracy and partially removes the effects produced by the lateral heat diffusion.
\end{abstract}

\section{INTRODUCTION}

The main ONERA/L3C contribution in the Non Destructive field lies in the techniques of the Stimulated Infrared Thermography (TIS) which consist in a pulse uniform illumination of the surface of the studied specimen, followed by the analysis of its InfraRed (IR) emission as a function of time /1/. Section 2 of this paper is devoted to the recent improvements brought by our group to this analysis and which allows to strongly decrease the effects of the lateral heat diffusion (3-D effects). As a consequence, the method leads to a high accuracy as regards the identified in-depth position of the defects, and to a better identified defect shape (see section 3 ). The advantages of this new inversion will be assessed, by performing it on artificial and natural impact defects present in composite materials.

\section{TIS EARLY DETECTION}

\subsection{Industrial set up}

The set-up used in the experiments described in this paper, corresponds to the front surface configuration, i.e. illumination and detection on the same surface. The pulsed sources available in our system can be either flashes (pulse duration $4 \mathrm{~ms}$ ) or continuous IR lamps $(48 \mathrm{~kW}$ ), the pulse being achieved, in that case, by the opening/closing of mechanical shutters electromechanically driven (the smallest pulse duration obtained with this system is $200 \mathrm{~ms}$ ). An AGEMA $880 \mathrm{LW}$ records the surface temperature as a function of time during periods of times up to $10 \mathrm{mn}$ after the pulse illumination. For instance, when placed at $1.2 \mathrm{~m}$ from the sample surface, the system allows to obtain a field of view of $20 \mathrm{~cm}$ and a spatial resolution of $2 \mathrm{~mm}$ with the objective of $12^{\circ}$ used for these experiments.

\section{2..2. Inversion using the early detection}

The detection and the characterization of the resistive subsurface defects is achieved by seeking local emergence of thermal contrast after the pulse illumination, i.e. an increase of the local temperature above the defect with respect to the temperature in a sound region, (figure 1a). 
Generally, the depth and the resistance of the defect are deduced from the value and the time of the maximum contrast $/ 1 \%$. This search is made pixel by pixel and finally leads to two synthetic images, respectively for the local depths and resistances of the subsurface defects. An alternative consists in the detection of the time corresponding to half the development of the contrast $/ 2 /$. The deeper the defects are, the longer these characteristic times are, with an important lateral heat diffusion as a consequence. Under these conditions, the inversion provides an underestimation of both the depths and the thermal resistances of the detected defects.

a) Schematic explanations of the two detections

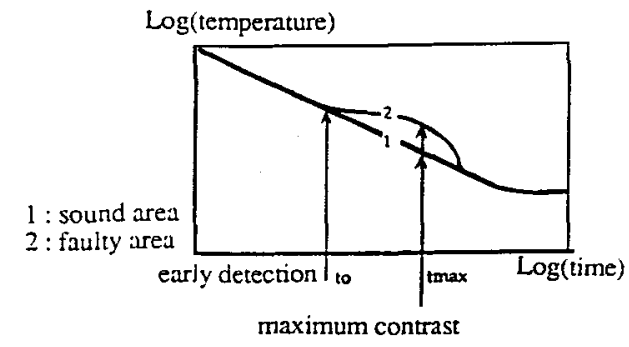

b) Definition of the detection threshold, $\partial \mathrm{T}$ being the noise

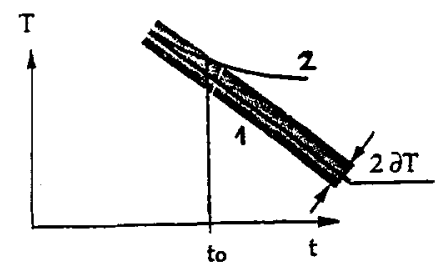

Figure 1

Thermograms of sound and faulty areas

In order to reduce the importance of the lateral diffusion effects, it is obvious that the detection of the thermal contrast should be achieved as early as possible. The threshold of detection is depending upon the noise level of the experiment, $\partial \mathrm{T}(\mathrm{t})$. Let us express this threshold, DT, as a percentage of the temperature above a sound region $T_{\text {ref }}(t)$ (more precisely the increase of temperature with respect to the temperature before the illumination):

$$
D T=K \frac{\partial T(t)}{T_{r e f}(t)}
$$

This threshold is chosen very low, just a bit larger than noise, for instance 1, 3, or 5\%, by adjusting the factor $K(K>1)$. For a given threshold, the time variation of the temperature of each pixel, $T(t)$, is then analysed and compared with the time variation of the temperature of an area known to be sound, $T_{\text {ref }}(t)$. If $T(t)$ exceeds $T_{\text {ref }}(t)$ by more than $\left(D T * T_{\text {ref }}(t)\right)$, the pixel is recognized to be above a faulty area (see figure $1 \mathrm{~b}$ ).

This early detection is insensitive to the thermal resistance, since it has been demonstrated $/ 3 /$ that, for a given depth, the relative thermal contrasts related to different resistances are merged at short times (see figure 2). Thus a very simple relation was found, between the depth $\mathrm{z}$ of the defect, the threshold DT, the time $t_{0}$ at which the threshold is reached and the thermal diffusivity $\kappa$ of the material:

$$
\mathrm{z}=\sqrt{\mathrm{t}_{0} \kappa \operatorname{Ln}\left(\frac{2}{\mathrm{DT}}\right)}
$$

After this depth identification based on the early detection, the resistance is deduced from the maximum or half-maximum contrast.

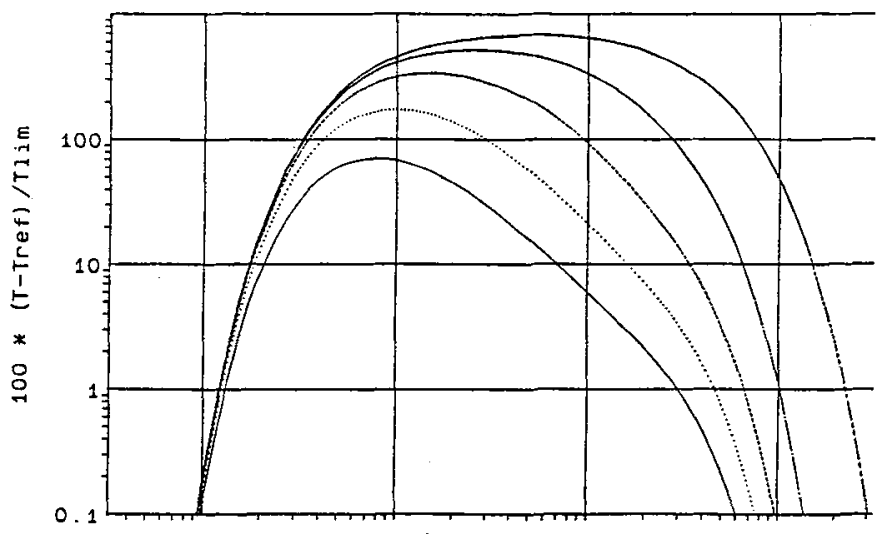

Figure 2

Relative thermal constrast vs time (thermal resistances: .32 to 32 times the resistance of the first layer) 


\section{RESULTS}

In order to demonstrate the good in-depth localisation of deep defects using the early detection , two artificial samples (called respectively 1 and 2 ) were prepared (figure 3 ):

- the sample 1 is a $5.25 \mathrm{~mm}$ thick plate of carbon epoxy containing small implants of teflon (thickness $80 \mu \mathrm{m}$ ) at depths varying from $0.4 \mathrm{~mm}$ to $4 \mathrm{~mm}$.

- the sample 2 is a disc of black Plexiglas $\otimes$ in the center of which concentric cavities of different depths were machined.

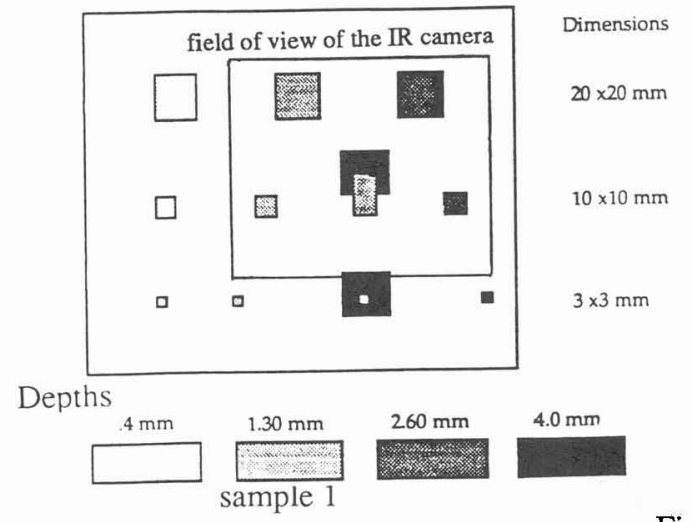

Figure $\overline{3}$

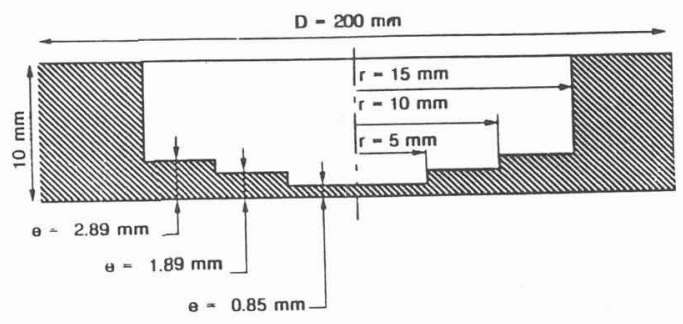

Artificial samples

Figure 4 shows the in-depth TIS image deduced from the early detection inversion and a comparison between the results of the half-maximum contrast and early detection methods of inversion in which the depths, identified in the centers of the defects, are plotted as functions of the true depths.

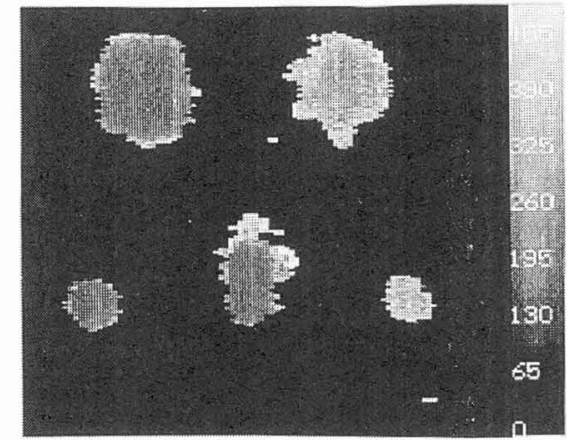

TIS in-depth image by the early detection Scale in tens of $\mu \mathrm{m}$

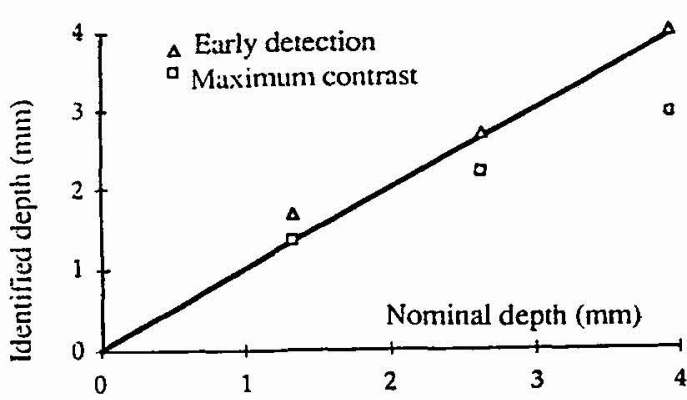

Early detection compared with halfmaximum contrast inversion

Figure 4

TIS in-depth inversion for sample 1

The improvements brought by the early detection are even more obvious in figure 5 obtained with the sample $2:$ i) the profiles of the concentric cavities are much more precise in the case of the early detection provided that the threshold is kept above the noise level (a deterioration of the results is observed when the threshold is taken smaller than $3 \%$ ), ii) the location depth of the first interface is very precisely determined.

The last example is a piece of a composite airfoil impacted in several points with known impulses. In carbon epoxy composites, the defects produced by impacts are quite dangerous because, generally, they do not let any visible traces at the surface, even when large multidelaminations are present in the thickness of the material /4/. The quantitative NDT problem to be solved here, is more the evaluation as accurately as possible of the global extension of the internal damages than the exact reconstruction of the shape of each delamination. 


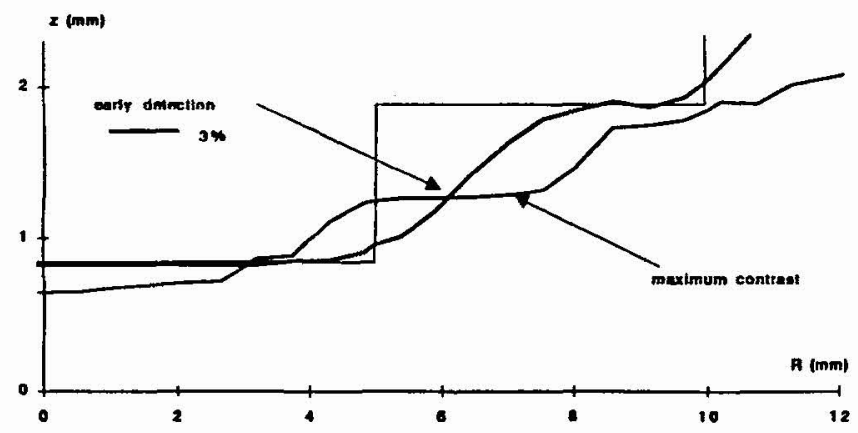

Figure 5

In-depth inversions by early detection and maximum contarst with sample 2 .

The comparison between the TIS and ultrasonics in-depth images showed that the TIS early detection method was able to restore quantitatively the extension of this damaged area within an incertainty (by default) of $5 \%$. This very good result proves that the lateral heat diffusion effect is well reduced by the inversion procedure. Figure 6 presents the projections of the delaminated volume determined from two TIS experiments, one on the impacted face, one on the opposite face.
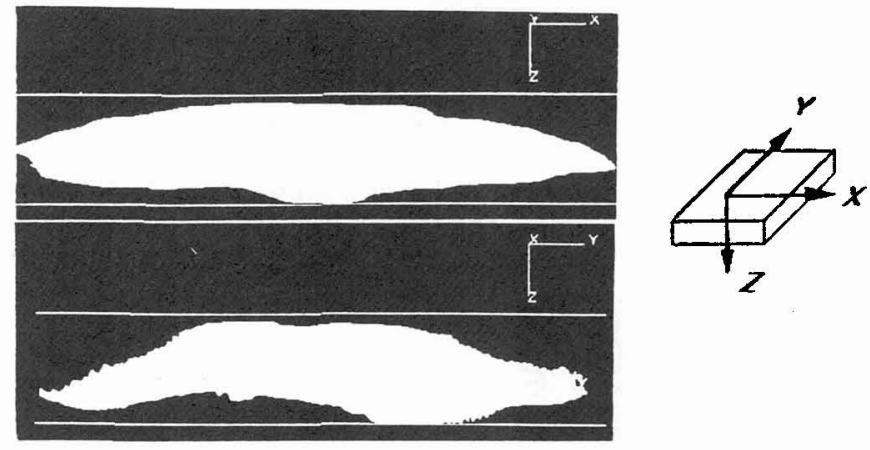

Figure 6

Projections of an early detection TIS reconstruction of an impact defect in a composite

\section{CONCLUSION}

The TIS method can be used to retrieve rapidly and accurately depths and thermal resistances of defects provided that a good inversion procedure is chosen. The early contrast method for depth combined with the half-maximum contrast method for resistance, presents the advantage to strongly decreasing the lateral diffusion effects.

In the special case of the quantitative characterization of impact damages in composites, the TIS method appears very competitive with ultrasonics since it provides, in a much shorter time, realistic values for the damage extension .

\section{REFERENCES}

/1/D. Balageas, A. Déom and D. Boscher, Materials Evaluation, 45, 461, 1987.

12/ J.C. Krapez, D. Boscher, P. Delpech, A. Déom, G. Gardette and D. Balageas, Proceedings of QIRT 92, Eurotherm Seminar Series 27, Editions Européennes Thermique et Industrie, Paris 1992.

13/ J.C. Krapez, Ph. D. Thesis, "Contribution à la caractérisation des défauts de type délaminage ou cavité par thermographie stimulée", Ecole Centrale de Paris, 1991.

/4/ G. Tober and R. Henrich, "In-Service Inspection concept for impact damage on CFRP structures", International Conference on Nondestructive Inspection, AAAF Proceedings, Paris 1991. 